\title{
Application of Enzymatically Treated Lignin Oligomers as Lignopolyols For A Full Replacement of Commercial Polyols in Polyurethane Foam Formulation
}

\author{
Joana Antunes, Thomas Levée and Petri Ihalainen* \\ MetGen Oy, Finland \\ *Corresponding author: Petri Ihalainen, MetGen Oy, Finland
}

\section{ARTICLE INFO}

Received: 隠 December 12, 2019

Published: 櫘 December 18, 2019

Citation: Joana Antunes, Thomas Levée, Petri Ihalainen. Application of Enzymatically Treated Lignin Oligomers as Lignopolyols For A Full Replacement of Commercial Polyols in Polyurethane Foam Formulation. Biomed J Sci \& Tech Res 24(1)-2019. BJSTR. MS.ID.003985.

\section{ABSTRACT}

Lignin has shown to have a great potential in replacing oil in many applications, including resins, polyols, polymers, coatings, and composites. The current case study describes the application of the selected lignin oligomeric fraction produced by a novel enzymatic lignin fractionation process $\left(\right.$ METNIN $^{\mathrm{TM}}$ ) as a suitable lignopolyol to completely replace a commercial polyol in polyurethane rigid foam formulations. More specifically, the preparation of liquid lignopolyols with a high lignin content (up to 40\%) by oxypropylation and its full utilization in the polyurethane rigid foam formulation was successfully demonstrated. In addition, selected technical specifications of foam demonstrators were characterized, including closed cell count, water uptake and compression characteristics. These specifications were all within industrial standards for rigid foam applications. The lignin loading in the lignopolyol was a major factor determining the properties of the foam and further studies are needed to further optimised and fully validate the specifications.
\end{abstract}

Keywords: Enzyme; Oxidation; Lignin; Depolymerisation; Polyol; Polyurethane foam

\section{Introduction}

Lignin valorization to added-value products has been a longstanding challenge of biorefineries. Most commonly the lignin side stream from biofuel and biorefinery plants is simply dried and burnt as bio-energy carrier in incineration facilities or co-generation units to generate useful secondary energy (e.g. heat and electricity). However, lignin valorization is mandatory for the commercially feasible conversion of plant biomass into industrial and consumer goods [1]. Lignin has shown to have great potential in replacing oil in many applications, including resins, polyols, polymers, coatings, and composites [2]. The key to success is to refine the complex molecules to have specific chemical characteristics that match the end-user application need. Recently, the integration of a lignin polymer as an inactive filler or an active polyol component in Polyurethane (PUR) foam formulations have gained great interest, both in academic and industrial sectors [3,4]. Polyurethane products can be found in building and construction, transportation, furniture and bedding, appliances, packaging, textiles, fibers \& apparel, machinery \& foundry, electronics, footwear. In addition, polyurethanes are commonly used in several medical applications including catheter and general-purpose tubing, hospital bedding, surgical drapes, wound dressings, as well as in a variety of injection molded devices. The current polyols used in PUR manufacture are of fossil origin and do not possess flame retardant properties, leading to the addition of synthetic retardants (typically halogenated organo-phosphates) to PUR mixtures with health concerns. The lignin-based polyol (lignopolyol) bioequivalent possesses intrinsic flame-retardant properties due to its phenol-based structure, potential serving as a drop-in replacement of fossil polyols in PUR foam manufacturing. However, to this date, rather poor reactivity and heterogeneous and complex structure of lignin polymer have restricted its wide-spread application in PUR applications.

Despite recent advances in catalytic processes for the valorization of lignin into materials and chemicals, still no established technology exists for its efficient depolymerization and 
reactivity enhancement $[5,6]$. This is due to harsh conditions for lignin isolation together with the prevalence of highly recalcitrant intra-molecular lignin linkages, and repolymerization tendency of phenoxy radicals. Enzymatic depolymerization of lignin is envisaged as one of the potential breakthrough applications for lignin valorization [7]. However, matching the optimal operation conditions of the enzyme with the optimal processibility of lignin has been a challenge. Recently, alkaliphilic laccase enabling the enzymatic operations at the conditions to better match the optimal processibility of crude lignin, i.e. alkaline aqueous conditions $\mathrm{(pH}$ 10-11) has been demonstrated [8]. In addition, a novel lignin valorization technology utilizing alkaliphilic laccases for the enzymatic oxidation of lignin in alkaline aqueous conditions $\mathrm{pH}$ 10-11) combined with cascading membrane operations has been recently introduced by MetGen Oy [9].

This technology, called METNIN ${ }^{\mathrm{TM}}$, has shown to able to produce different molecular size lignin fractions (from oligomeric down to a mixture of tri-, di and monomeric units) with a distinct molecular weight distribution and a low polydispersity together with more favourable physicochemical properties. METNIN ${ }^{\mathrm{TM}}$ process enables the utilization and potentially better applicability of lignin in a variety of application areas, including polyurethane foams. The current case study describes the application of a selected lignin oligomeric fraction produced by METNIN ${ }^{\mathrm{TM}}$ process as a suitable lignopolyol to completely replace a commercial polyol in PUR foam formulation.
More specifically, the preparation of liquid lignopolyols by oxypropylation of METNIN ${ }^{\mathrm{TM}}$ oligomeric lignin fraction and its full utilization in the polyurethane rigid foam formulation is demonstrated. In addition, selected technical specifications of PUR demonstrators are characterized.

\section{Material and Methods}

\section{Lignin Characteristics}

A crude lignin extracted from a woody (birch) biomass was supplied by SWEETWOODS project [10]. The selected lignin oligomeric fraction was obtained by the fractionation of the crude lignin by METNIN ${ }^{\mathrm{TM}}$ enzymatic lignin valorization process (MetGen Oy, Finland) [9]. METNIN ${ }^{\mathrm{TM}}$ process produces an aqueous alkaline solution of lignin fractions ( $\mathrm{pH} 10-11$ ). For this study, METNIN ${ }^{\mathrm{TM}}$ lignin fraction was extracted as a dry powder using acid precipitation protocol adapted from Sameni et al. [11]. An example of the sample is shown in Figure 1A. Selected physicochemical properties of METNIN $^{\mathrm{TM}}$ lignin oligomer fraction after extraction are collected in Table 1. METNIN ${ }^{\mathrm{TM}}$ lignin oligomer shows high purity (>95\%) with low ash and carbohydrate content. Average molecular weight (Mw) and polydispersity index (PDI) were determined by HPLC chromatographer 1200 CompactLC with UV detector (Agilent Technologies), equipped with size exclusion column set MCX $1000 \AA+100000 \AA$ $10 \mu \mathrm{m}, 8 \times 300 \mathrm{~mm}$ and with pre-column MCX $10 \mu \mathrm{m}, 8 \times 50 \mathrm{~mm}$ (Polymer Standards Service). Isocratic mode with $0.1 \mathrm{M} \mathrm{NaOH}$ eluent flow $0.6 \mathrm{~mL} / \mathrm{min}$ at $\mathrm{RT}$ was used with run time of $45 \mathrm{~min}$.
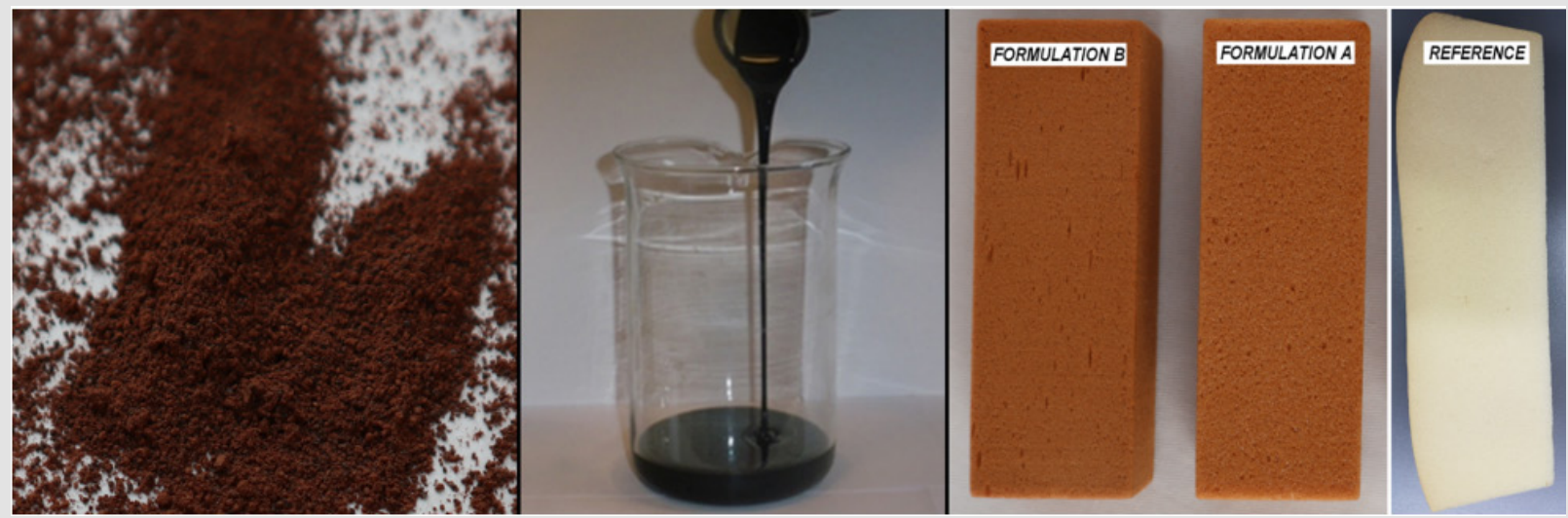

Figure 1: LEFT: METNINTM lignin oligomer (as a dry powder) after acid precipitation. MIDDLE: Lignopolyol liquid after oxypropylation reaction (Formulation A). RIGHT: Polyurethane foam blocks with Formulation A, Formulation B and Reference (with commercial polyols).

Table 1: Selected physicochemical characteristics and composition of METNINTM lignin oligomer. Values for acetylated hydroxyl group $\left(\mathrm{OH}_{\text {acet }}\right)$, carboxylic group $\left(\mathrm{OH}_{\mathrm{COOH}}\right)$, phenolic group $\left(\mathrm{OH}_{\mathrm{ph}}\right)$, aliphatic $\mathrm{OH}\left(\mathrm{OH}_{\text {aliph }}\right)$, methoxy $\left(\mathrm{OCH}_{3}\right)$ content, average molecular weight $(\mathrm{Mw})$, polydispersity index (PDI), glass transition temperature $\left(\mathrm{T}_{\mathrm{g}}\right)$ and temperature at which $5 \%$ of weight loss is observed (T5\%) are presented- .

\begin{tabular}{|c|c|c|c|c|c|c|c|c|c|}
\hline \multicolumn{6}{|c|}{ Content on dry ash free sample, [mmol/g] } & \multicolumn{2}{|c|}{ Molecular weight } & \multicolumn{2}{|c|}{ Thermal properties } \\
\hline $\mathbf{O H}_{\text {acet }}$ & $\mathbf{O H}_{\mathrm{COOH}}$ & $\mathbf{O H}_{\mathrm{ph}}$ & $\mathbf{O H}_{\text {aliph }}$ & $\mathbf{O H}_{\text {total }}$ & $\mathbf{O C H}_{3}$ & Mw & PDI & $\mathbf{T}_{\mathrm{g}}$ & T5\% \\
\hline $5.1 \pm 0.25$ & $1.28 \pm 0.036$ & 1.7 & 4.7 & 7.7 & $7.6 \pm 0.02$ & $2.3 \mathrm{kDa}$ & 2.2 & $141^{\circ} \mathrm{C}$ & $247^{\circ} \mathrm{C}$ \\
\hline \multicolumn{10}{|c|}{ METNIN $^{\mathrm{TM}}$ lignin oligomer composition by dry weight basis [\%] } \\
\hline \multicolumn{3}{|c|}{ Total lignin } & \multicolumn{4}{|c|}{ Ash } & \multicolumn{3}{|c|}{ Carbohydrates } \\
\hline \multicolumn{3}{|c|}{95.1} & \multicolumn{4}{|c|}{0.5} & \multicolumn{3}{|c|}{0.32} \\
\hline
\end{tabular}


Lignin samples were monitored at $358 \mathrm{~nm}$. Molecular mass standards (polystyrene sulfonate sodium salt standards $\mathrm{Mp}=\sim 0.9$ to $976 \mathrm{kDa}$, Polymer Standards Service) were monitored at 254 nm. Lignin model compounds with MW between 180 and $638 \mathrm{Da}$ monitored at $358 \mathrm{~nm}$ were used to extend the standard curve. Data was acquired with EzChrom Elite Compact software. Ash content was determined by EN 14775:2009 standard. Total lignin content is the sum of Klason (acid insoluble) lignin content determined by the gravimetric method according to TAPPI T222 standard and acid soluble lignin content determined by the UV spectrophotometric method according to TAPPI 250 UM standard. Carbohydrate (i.e. monomeric sugars content after carbohydrate complex hydrolysis) was determined by a gas chromatographic analysis with modified alditol acetate method [12]. Acetylated $\mathrm{OH}$ group $\left(\mathrm{OH}_{\text {acet }}\right)$ content was determined by the modified Verley and Bolsing method [13]. Methoxy $\left(\mathrm{OCH}_{3}\right)$ content was determined by Zeisel-ViebockSchwapapch method [13]. Total hydroxylic group $\left(\mathrm{OH}_{\text {total }}\right)$ content was determined by the wet chemistry method (acetylation by acetic anhydride followed by free acid potentiometric titration by $0.1 \mathrm{M} \mathrm{NaOH}$ ) [13].

Carboxylic group $\left(\mathrm{OH}_{\mathrm{COOH}}\right)$ content was determined by wet chemistry chemisorption method using calcium acetate. The total acidic groups (phenolic + carboxylic) content was determined by the acid-base back conductometric titration method [13]. The content of phenolic groups $\left(\mathrm{OH}_{\mathrm{ph}}\right)$ was calculated from the difference between the values of conductometric and chemisorption methods. The aliphatic $\mathrm{OH}\left(\mathrm{OH}_{\text {aliph }}\right)$ content was calculated by the following relation: $\mathrm{OH}_{\text {aliph }}=\mathrm{OH}_{\text {acet }}+\mathrm{OH}_{\mathrm{COOH}}-\mathrm{OH}_{\mathrm{ph}}$. analysis (TGA) to determine the temperature at which $5 \%$ of weight loss is observed (T5\%) was conducted in following conditions: sample weight 8.0-8.5 $\mathrm{mg}$, heating rate $10^{\circ} \mathrm{C} / \mathrm{min}$, atmosphere nitrogen. The differential scanning calorimetry (DSC) used to determine the glass transition temperature ( $\mathrm{Tg}$ ) was performed in the temperature range of $0-180^{\circ} \mathrm{C}$ with a heating rate of $10^{\circ} \mathrm{C} / \mathrm{min}$.

\section{Lignopolyl Preparation and Characterisation}

Liquid lignopolyols were obtained by oxypropylation of the lignin fraction in accordance with anionic polymerization in the presence of potassium hydroxide as a catalyst in high pressure laboratory scale (1 L) PARR reactor equipped by an oil thermostat [14]. The calculated amount of propylene oxide (PO), lignin (L) potassium hydroxide ( $\mathrm{KOH}, 5 \%$ on DM of lignin) were loaded into the reactor, which was sealed, stirred at room temperature during 40 minutes then heated under stirring using oil thermostat with external round to $160-180^{\circ} \mathrm{C}$ when the exothermic process has started. The external heating was turned off and the reaction proceeded in spontaneous autothermic regimes. Due to PO uptake on the conversion pressure in the reactor dropped to a value closed to atmospheric pressure.

The temperature inside of the reactor was first increased significantly and then lowered due to dissipation of heat in the environment. After cooling, the $\mathrm{KOH}$ was neutralized by acetic acid and the product was treated during 2 hours in vacuum rotation evaporator to eliminate the water formed at neutralization of $\mathrm{KOH}$. Dark brown viscous liquids (lignopolyols) completely free of solids were obtained in all cases. The lignin content $(\mathrm{L} / \mathrm{L}+$ PO) in the reaction was between $20-40 \%$. The compositions of reaction mixtures used for investigation are presented in Table 2. Oxypropylation parameters were adjusted based on the lignin content in the reaction mixture Table 3 . Adjustable parameters included maximal pressure in the reactor $\left(\mathrm{P}_{\max }\right)$, maximal temperature $\left(\mathrm{T}_{\max }\right)$, the temperature at which the exothermic process was started $\left(\mathrm{TP}_{\max }\right)$ and time necessary for a two-fold decrease of maximal pressure in reactor $\left(\mathrm{t}_{0.5}\right)[15]$

Table 2: The composition of reaction mixtures loaded in PARR reactor for lignopolyols synthesis.

\begin{tabular}{|c|c|c|c|}
\hline \multirow{2}{*}{ Component } & \multicolumn{3}{|c|}{ Content [g] } \\
\cline { 2 - 4 } & Lignin content 20\% & Lignin content 30\% & Lignin content 40\% \\
\hline Propylene oxide & 140 & 140 & 120 \\
\hline Lignin (5\% water content) & 36.8 & 63.2 & 84.3 \\
\hline
\end{tabular}

Table 3: Dependence of oxypropylation parameters on lignin content in the reaction mixture. Values for the maximal pressure in the reactor $\left(\mathrm{P}_{\max }\right)$, maximal temperature $\left(\mathrm{T}_{\max }\right)$, the temperature at which the exothermic process was started $\left(\mathrm{T}_{\mathrm{P}, \max }\right)$ and time necessary for a two-fold decrease of maximal pressure in the reactor $\left(t_{0.5}\right)$ are presented.

\begin{tabular}{|c|c|c|c|c|}
\hline $\begin{array}{c}\text { Lignin content [L/(L+P0), } \\
\text { \%] }\end{array}$ & $\mathbf{P}_{\max }[\mathbf{b a r}]$ & $\left.\mathbf{T}_{\max }{ }^{\circ}{ }^{\circ} \mathbf{C}\right]$ & $\mathbf{T}_{\text {P,max }}\left[{ }^{\circ} \mathbf{C}\right]$ & $\mathbf{t}_{\mathbf{0 . 5}}[\mathbf{m i n}]$ \\
\hline 20 & 23.9 & 215 & 165 & 5.0 \\
\hline 30 & 28.9 & 254 & 185 & 2.6 \\
\hline 40 & 19.6 & 214 & 165 & 5.1 \\
\hline
\end{tabular}

\section{Polyurethane Foam Formulation and Characterisation}

PUR foam compositions were formulated by a complete replacement of commercial glycerol-based polyether and sorbitol based polyether with lignopolyols. All foam demonstrators were obtained by the free rising method [15]. Composition of PUR foam formulations are listed in Table 4. In Formulation B, an increase amount of water (as a chemical blowing agent) was added due its high lignin content $(40 \%)$ and low density $\left(\sim 30 \mathrm{~kg} / \mathrm{m}^{3}\right)$ to ensure 
the stability PUR foams without shrinkage. The amount of polymeric diphenylmethane diisocyanate (PMDI, NCO 31.5\%) in each composition is corrected by using the isocyanate index $(\mathrm{NCO} / \mathrm{OH}$ ratio) of 1.15. All foams were obtained by the free rising method[13]. The necessary amount of PMDI was added to the mixture of all components excluding isocyanate and mixed for $15 \mathrm{~s}$ at the rotation speed of $1750 \mathrm{rpm}$ and then poured into plastic bags of different volume ( $0.5 \mathrm{l}$ to $5 \mathrm{l}$ ) for foaming. Lignin-based polyols PU foams are made by reacting polyols with diisocyanates. The hydroxyl groups of substituted polyols react with the isocyanate groups to form irreversible urethane linkages. Blowing agents $\left(\mathrm{CO}_{2}\right)$ and additives, such as flame retardants, are necessary to produce the foam's cellular structure and confer the desired properties. The foams samples were tested after one week of storage. Apparent density, closed cell content, water absorption was determined according to ISO 845:2009, ISO 4590:2003 and ISO 2896:2001, respectively. The compression strength $(\sigma)$ and Young's modulus at compression (E) of PUR foams were performed in parallel $(\mathrm{x})$ and perpendicu$\operatorname{lar}(\mathrm{z})$ to foaming directions by testing machine Zwick/Roell Z 100 according to LVS EN ISO 844:2009 standards. However, to correctly compare the strength and modulus of PUR foams the values were normalized(n) to an average density of $40 \mathrm{~kg} / \mathrm{m}^{3}$. Here, it was also assumed that in the density range of $32-52 \mathrm{~kg} / \mathrm{m}^{3}$ dependence of foams characteristics on their density was directly proportional for each PUR matrix [16]. Normalisation will remove the dependence of the density on compression characteristics of material.

Table 4: PUR foams compositions for different formulations. Reference formulation is using commercial polyols and Formulation A and Formulation B lignin-based polyols.

\begin{tabular}{|c|c|c|c|c|}
\hline \multirow{2}{*}{ Component } & \multirow{2}{*}{ Supplier } & \multicolumn{3}{|c|}{ Content, part by weight } \\
\hline & & Reference & Formulation A & Formulation B \\
\hline Lupranol 3300 & BASF & 70 & - & - \\
\hline Lupranol 3422 & BASF & 30 & - & - \\
\hline Lignopolyol (L/(L+PO)=30\%) & IWC & - & 100 & - \\
\hline Lignopolyol $(\mathrm{L} /(\mathrm{L}+\mathrm{PO})=40 \%$ & IWC & - & - & 100 \\
\hline Potasium acetate & Sigma & 0.8 & - & - \\
\hline Water & - & 0.5 & 0.5 & 0.65 \\
\hline Amine catalyst pollycat 5 & Momentive & 0.5 & 0.5 & 0.5 \\
\hline Plasticizer Trihloropylphosphate & Albemarle & 25 & 25 & 25 \\
\hline Surfactant Niax Silicone L6915 & Momentive & 1.5 & 1.5 & 1.5 \\
\hline Blowing agent Solkane 365/227 & Solvay & 20 & 20 & 20 \\
\hline Isocyanate IsoPMDI 92140 & BASF & 131 & 104.8 & 119.4 \\
\hline Parameters & & \multicolumn{3}{|c|}{ Averages } \\
\hline $\mathrm{NCO} / \mathrm{OH}$ ratio & & 1.15 & 1.15 & 1.15 \\
\hline $\begin{array}{l}\text { Level of commercial polyols substitution by } \\
\text { lignopolyols, } \%\end{array}$ & - & 0 & 100 & 100 \\
\hline Lignopolyol content in foam, $\%$ & - & 0 & 39.6 & 37.4 \\
\hline Isocyanate content in foam, $\%$ & & 46.9 & 41.6 & 44.7 \\
\hline
\end{tabular}

\section{Results and Discussion}

The physicochemical characteristics of synthesised lignopolyols are summarised in Table 5. Results show that the increased amount of METNIN ${ }^{\mathrm{TM}}$ lignin oligomer in the reaction mixture during oxypropylation process increases the hydroxyl value (OHV), potassium acetate (KAc) content and viscosity. Hydroxyl values of polyols used in rigid $\mathrm{PU}$ foams formulation are in the range 300-800 $\mathrm{mg} \mathrm{KOH} / \mathrm{g}$ and viscosity should be below $300000 \mathrm{mPa} \cdot \mathrm{s}$ (at $25^{\circ} \mathrm{C}$ ) $[17,18]$. Lignopolyol samples containing $30 \%$ and $40 \%$ of lignin meet these requirements. Thus, these two lignopolyol samples were selected to be applied in the production of PUR demonstrators. Compared to reference formulation, a significant decrease both in the start time and the gel time of PUR foaming was observed for formulations containing lignopolyols (Table 6). This indicates that lignopolyols were more reactive towards isocyanate compared to the commercial polyethers presented in reference formulation. In addition, the lignopolyol with the higher lignin content showed higher reactivity in the PUR foam system.

Table 5: Physicochemical characteristics of lignopolyols.

\begin{tabular}{|c|c|c|c|}
\hline \multirow{2}{*}{ Property } & \multicolumn{3}{|c|}{ Lignin content [L/(L+PO), \%] } \\
\cline { 2 - 4 } & $\mathbf{2 0}$ & $\mathbf{3 0}$ & $\mathbf{4 0}$ \\
\hline OHV [mg KOH/g] & 268.3 & 352.2 & 393.3 \\
\hline Equivalent weight [g/eq] & 209.1 & 159.3 & 142.9 \\
\hline KAc content [\%] & 1.39 & 2.62 & 3.50 \\
\hline $\begin{array}{c}\text { Water content (by Fisher } \\
\text { titration) [\%] }\end{array}$ & 0.129 & 0.133 & 0.131 \\
\hline Viscosity at $25^{\circ} \mathrm{C}[\mathrm{mPa} \cdot \mathrm{s}]$ & 1630 & 2624 & 63339 \\
\hline
\end{tabular}


Table 6: The foaming parameters, apparent density, closed cell content and water absorption for PUR foams.

\begin{tabular}{|c|c|c|c|c|c|}
\hline \multirow{2}{*}{ PUR foam compositions } & \multicolumn{2}{|c|}{ Foaming parameters } & \multicolumn{3}{c|}{ Foam properties } \\
\cline { 2 - 6 } & Start time [s] & Gel time [s] & Density [kg/ $\mathbf{m}^{3}$ ] & $\begin{array}{c}\text { Closed cell content } \\
\text { [vol.\%] }\end{array}$ & $\begin{array}{c}\text { Water absorption (7 days) } \\
\text { [vol.\%] }\end{array}$ \\
\hline Reference & 25 & 265 & $53 \pm 2$ & 91 & $5.82 \pm 0.16$ \\
\hline Formulation A & 18 & 65 & $40 \pm 1$ & 94 & $4.59 \pm 0.12$ \\
\hline Formulation B & 18 & 45 & $32 \pm 1$ & 93 & $3.92 \pm 0.20$ \\
\hline
\end{tabular}

The higher reactivity of PUR foam compositions containing lignopolyols compared to reference formulation resulted to a higher rate of heat release, a higher temperature in foaming block and as a sequence the higher volume that occupied the volatiles formed in the result of water reaction with PMDI (i.e. carbon dioxide) and physical blowing agents (i.e. Freon) evaporation. As the result, the apparent density of Formulation A was lower in comparison with less reactive reference PUR foam composition. In the case of Formulation B, the lower density was achieved by the increased water content ( 0.5 versus 0.65 ) in the formulation (Table 4 ). Lower density is beneficial as it is known that heat insulation properties of PUR foams are deteriorating with with increased foam density[18]. No traces of foams shrinkage were observed with any of the formulations, even with Formulation B with very low density.

Results show that over 90\% closed cell content was achieved with all PUR foam formulations (Table 6). The high closed cell content indicates that crosslinking reactions leading to the polymeric network strength development and subsequent process of gaseous phase liberation were in the balance to reach optimal closed cell structure [18]. This is one of the major requirement influencing the heat isolation properties of PUR foams.

Water absorption of PUR foams is another parameter influencing the level of heat isolation characteristics, with a lower water uptake enabling prolonged exploitation duration to moist conditions [18]. The water absorption values for PUR foams containing a lignopolyol were lower than those of the reference sample, indicating a more hydrophobic character of the former (Table 6). In addition, the water uptake decreases with the increasing lignin content in the polyol. Compression characteristics of PUR foams are shown in Table 7. The deformation characteristics of the PUR foam are dependent on its density as well as on the chemical composition and structure of polymeric matrix [18].

The apparent density of foams obtained varied in the range $32-49 \mathrm{~kg} / \mathrm{m}^{3}$ that meet the requirements for PUR foams usable for heat isolation in buildings (normally ranges between 30 to $45 \mathrm{~kg}$ / $\mathrm{m}^{3}$ ) [19]. In all samples, deformation characteristics in foaming direction exceed those in the direction perpendicular to foaming (Table 7). This is explained by the elongation of cells foams in foaming directions, leading to the appearance of anisotropy of material characteristics. The anisotropy of strength and modulus was the most pronounced for Formulation B (40\% of lignin in lignopolyol). The compression characteristics in the foaming direction of PUR foam using Formulation B, which are the dominant property of the PUR foam, are higher compared to reference formulation and Formulation B. On the other hand, the opposite is true for the compression characteristics in perpendicular direction.

Table 7: Compression characteristics of PUR foams., i.e. compression strength $(\sigma)$ and Young's modulus at compression (E) in parallel ( $\mathrm{x}$ ) and perpendicular $(\mathrm{z})$ to the foaming direction. Also shown are the corresponding normalized (n) values.

\begin{tabular}{|c|c|c|c|c|c|c|}
\hline \multirow{2}{*}{ PUR foam formulation } & \multirow{2}{*}{ Density $\left[\mathrm{kg} / \mathrm{m}^{3}\right]$} & \multicolumn{5}{|c|}{ Compression characteristics [MPa] } \\
\hline & & $\sigma_{\mathrm{x}}$ & $E_{x}$ & $\sigma_{\mathrm{z}}$ & $\mathrm{E}_{\mathrm{z}}$ & $\sigma_{\mathrm{x}} / \sigma_{\mathrm{z}}$ \\
\hline Reference & 53 & $0.308 \pm 0.018$ & $9.26 \pm 0.86$ & $0.275 \pm 0.020$ & $6.94 \pm 0.42$ & 1.12 \\
\hline Formulation A & 43 & $0.152 \pm 0.016$ & $5.83 \pm 0.57$ & $0.142 \pm 0.015$ & $4.10 \pm 0.34$ & 1.07 \\
\hline \multirow[t]{3}{*}{ Formulation B } & 32 & $0.208 \pm 0.010$ & $8.16 \pm 0.47$ & $0.063 \pm 0.005$ & $1.19 \pm 0.03$ & 3.30 \\
\hline & \multicolumn{6}{|c|}{ Normalised compression characteristics [MPa] } \\
\hline & & $\sigma_{\mathrm{x}, \mathrm{n}}$ & $E_{x, n}$ & $\sigma_{z, \mathrm{n}}$ & \multicolumn{2}{|c|}{$\mathrm{E}_{\mathrm{z}, \mathrm{n}}$} \\
\hline Reference & 40 & 0.232 & 6.98 & 0.207 & \multicolumn{2}{|c|}{5.23} \\
\hline Formulation A & 40 & 0.141 & 5.42 & 0.132 & \multicolumn{2}{|c|}{3.79} \\
\hline Formulation B & 40 & 0.263 & 10.3 & 0.08 & \multicolumn{2}{|c|}{1.50} \\
\hline
\end{tabular}


One explanation for anisotropy behaviour could be the lower NCO conversion at the gel moment in lignopolyol due to its high functionality. As the result, a significant amount of heat was evolved after gel formation when the fluidity of the foaming system decreases dramatically and the growing of foam proceeded predominantly in a vertical direction. This process leads to deformation of closed cell form from spherical to ellipsoidal. Results show that the compression characteristics of PUR foams on the basis of lignopolyols with $30 \%$ of lignin content (Formulation A) in both directions were lower in the comparison with reference formulation-, whereas for the higher lignin content (Formulation B) the compression characteristics exceeded those of the reference -. In any case, the density and compression characteristics of both lignopolyol containing foams meet the requirement for PUR foams suitable for producing heat isolation in a building.

In conclusion, the case study presented here demonstrates the successful synthesis of lignin based polyols with high lignin content using METNIN $^{\mathrm{TM}}$ lignin oligomer and the subsequent application of the lignopolyol as a full replacement of commercial polyol in PUR foam demonstrator. In addition, the selected technical specifications of the rigid PUR foams are within the typical industrial requirements. In some cases, lignopolyol shows improved performance. However, for the full commercial validation, additional properties such as dimension stability at enhanced temperature, heat resistance, thermo-oxidative stability and fire resistance have to be determined. This is in work in progress and will be presented in further communications.

\section{Acknowledgement}

The funding from the Bio Based Industries join Undertaking under the European Union's Horizon 2020 research and innovation programme under grant agreement No. 792061 (SWEETWOODS) is acknowledged. It is recognized that results are based on the contractual work between MetGen Oy (Kaarina, Finland) and Latvian State Institute of Wood Chemistry (Riga, Latvia) by Prof. Galina Telysheva's group.

\section{Conflict of Interest}

The authors declare no conflict of interest.

\section{References}

1. S Xie, Arthur J, Ragauskas, JS Yuan (2016) Lignin Conversion: Opportunities and Challenges for the Integrated Biorefinery. Ind Biotechnol 12(3): 161-167.
2. DS Bajwa, G Pourhashem, AH Ullah, SG Bajwa (2019) A concise review of current lignin production, applications, products and their environmental impact. Ind Crops and Products 139.

3. NV Gama, A Ferreira, A Barros Timmons (2018) Polyurethane Foams: Past, Present, and Future. Materials 11(10).

4. Alinejad M, Henry C, Nikafshar S, Gondaliya A, Bagheri S, et al. (2019) Lignin-Based Polyurethanes: Opportunities for Bio-Based Foams, Elastomers, Coatings and Adhesives. Polymers 11(7): 1202-1223.

5. Z Sun, B Fridrich, A de Santi, S Elangovan, K Barta (2018) Bright Side of Lignin Depolymerization: Toward New Platform Chemicals. Chemical Reviews 118(2): 614-678.

6. Ł Klapiszewski, TJ Szalaty, T Jesionowski (2018) Depolymerization and Activation of Lignin: Current State of Knowledge and Perspectives. Intech Open.

7. J Becker, C Wittmann (2019) A field of dreams: Lignin valorization into chemicals, materials, fuels, and health-care products. Biotechnol Adv 37(6): 107360-107384

8. Veera Hämäläinen, Toni Grönroos, Anu Suonpää, Matti Wilhem Heikkilä, Bastiaan Romein, et al.(2018) Enzymatic process to unlock the lignin value. Front Bioeng Biotechnol 6(20): 1-10.

9. www.metgen.com

10. www.sweetwoods.eu

11.J Sameni, S Krigstin, D dos Santos Rosa, A Leao, M Sain (2014) Thermal Characteristics of Lignin Residue from Industrial Processes. BioResources 9(1): 725-737.

12. M Lauberts, L Lauberte, A Arshanitsa, T Dizhbite, G Dobele, et al. (2018). Structural transformations of wood and cereal biomass component induced by microwave assisted torrefaction with emphasis of extractable chemicals obtaining. J Anal Appl Pyrolysis 134: 1-11.

13. GF Zakis (1994) Functional Analysis of Lignins and their Derivatives. TAPPI Press.

14. B Berrima, G Mortha, S Boufi, E El Aloui, MN Belgacem (2016) Oxypropylation of Soda Lignin: Characterization and Application in Polyurethane Foams Production. Cellulose Chem Technol 50 (9-10): 941-950.

15. G Sung, H Choe, Y Choi, Jung Hyeun Kim (2018) Morphological, acoustical, and physical properties of free-rising polyurethane foams depending on the flow directions. Korean J Chem Eng 35(4): 1045-1052.

16.X Cao, LJ Lee, T Widya, C Masockso (2005) Polyurethane/clay nanocomposites foams: processing, structure and properties. Polymer 46(3): 775-783

17.P Furtwengler, L Avérous (2018) Renewable polyols for advanced polyurethane foams from diverse biomass resources. Polymer Chemistry (32): 4258-4287.

18.JM Buist (1978) Development in polyurethane. 1 Applied Science Publishers 1-290.

19. www.react-ite.eu 


\section{ISSN: 2574-1241}

DOI: 10.26717/BJSTR.2019.24.003985

Petri Ihalainen. Biomed J Sci \& Tech Res

(C) This work is licensed under Creative

Submission Link: https://biomedres.us/submit-manuscript.php

\begin{tabular}{ll} 
BIOMEDICAL & \multicolumn{1}{c}{ Assets of Publishing with us } \\
RESEARCHES & - Global archiving of articles \\
- Immediate, unrestricted online access \\
- Rigorous Peer Review Process \\
https://biomedres.us/
\end{tabular}

